Understanding Biology Using Peptides

Sylvie E. Blondelle (Editor)

American Peptide Society, 2005

\title{
Design and Study of Novel Peptide Inhibitors against the SARS- Coronavirus Spike Protein
}

\author{
Zhe Yan, Brian Tripet and Robert S. Hodges \\ Department of Biochemistry and Molecular Genetics. University of Colorado at Denver and \\ Health Sciences Center, Aurora, CO, 80045, USA
}

\section{Introduction}

Severe Acute Respiratory Syndrome (SARS) is an acute respiratory illness caused by infection with a novel coronavirus (SARS-CoV). Infection by SARS coronaviruses requires fusion of the viral and cellular membranes, which is mediated by the viral envelope Spike (S) glycoprotein and receptors on the target cell. The S protein contains two hydrophobic repeat regions, denoted HRN and HRC, which oligomerize the S glycoprotein into a trimer in the native state, and when activated collapse into a six-helix bundle structure driving fusion of the host and viral membranes. We and others have previously reported that the HR regions of SARS$\mathrm{CoV} \mathrm{S}$ protein can associate to form a very stable helical six-stranded structure and residues 902-950 in HRN and 1151-1185 in HRC were identified to be crucial for their interaction [1-4].

Due to the severity and mortality $(10 \%)$ witnessed in the fall of 2003 during the spread of the SARS-CoV pandemic, and the current lack of effective agents for the antiviral therapy of SARS-CoV infection, it has become imperative to learn as much as possible about this virus and the ability to prevent future infection. As successfully used

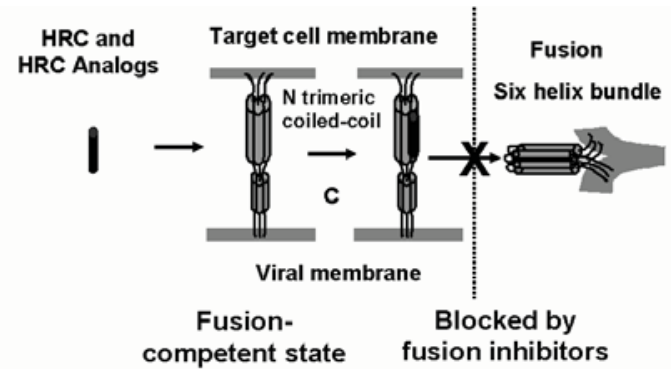
in fusion inhibitor design for Fig. 1. Schematic model illustrating the action of SARS-CoV fusion inhibitors that target HRN. HIV [5], peptides derived from HRC can bind to the transiently exposed HRN coiled-coil trimer and block the formation of the six-helical bundle (Fig. 1), which ultimately leads to a loss of membrane-fusion activity. In this study, HRN (902-950) peptide of SARS-CoV S protein was chosen as the target for testing the interaction of HRC analogs.

The 36-residue HRC peptide (1150-1185) was chosen as the region to design a series of HRC analogs, in order to increase their stability and binding affinity with HRN. These substitutions /modifications involved: (1) increasing helical propensity (HRC2 and HRC4); (2) increasing hydrophobicity in the hydrophobic core (HRC1 and HRC3); and (3) introducing a lactam bridge (HRC5). The sequences of these peptides are shown in Figure 2.

\section{Results and Discussion}

To examine the helical structure changes of the HRC analogs, we analyzed each peptide by circular dichroism spectroscopy (CD). Under physiological conditions, these analogs are well folded, soluble, have higher $\alpha$-helical content and are more stable than native HRC as expected (in Fig. 3A and Table 1). 


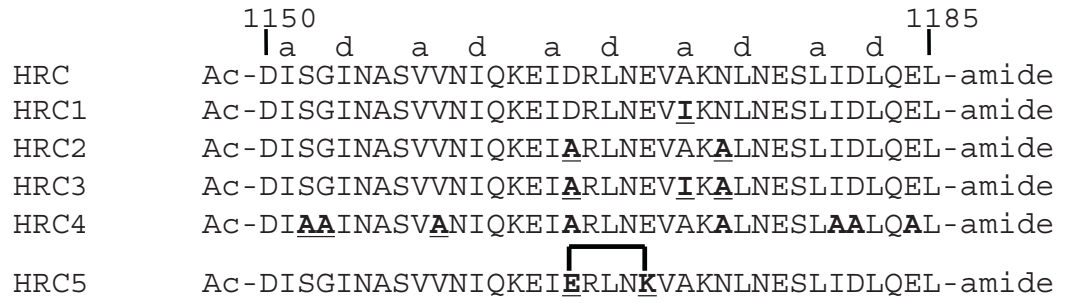

Fig. 2. Peptide sequences.
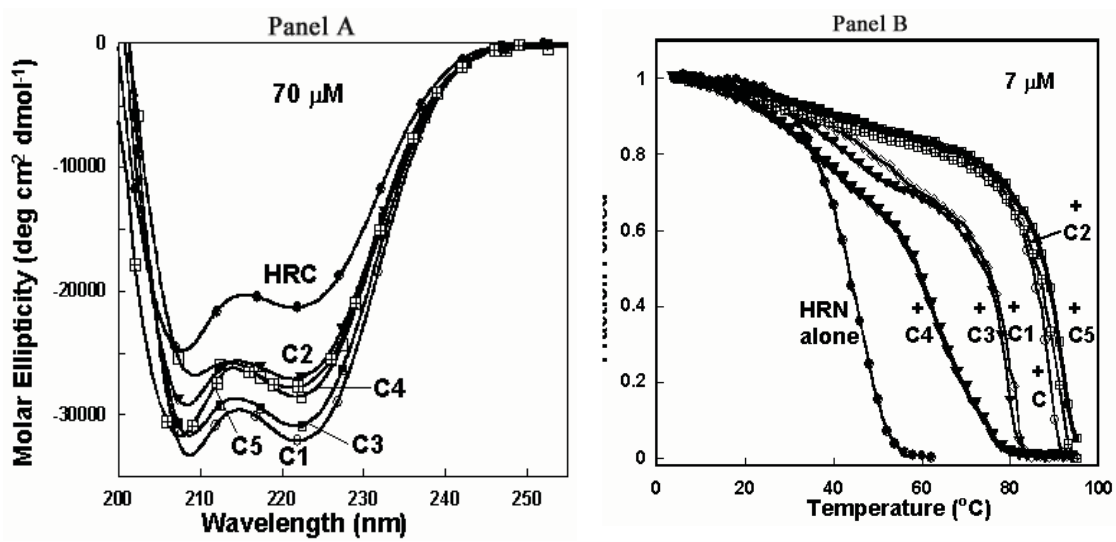

Fig. 3. CD analysis of HRC analogs and interaction with HRN.

To test the stability of HRN, HRC analogs, and complexes of HRN with HRC analogs, CD spectra at different temperatures were measured to determine the temperature denaturation profiles as illustrated in Figure 3B, and their Tm values are shown in Table 1. These results show that HRC and analogs can strongly bind to HRN. HRN-HRC5 complex was not completely unfolded, even at $95^{\circ} \mathrm{C}$. $\mathrm{HRC} 2$ has similar interaction with HRN as HRC. The complexes of HRN-HRC1 and HRN-HRC3 are less stable than HRNHRC. HRN-HRC4 is the least stable complex.

To verify complex formation between HRN and HRC analogs, we analyzed their interaction by

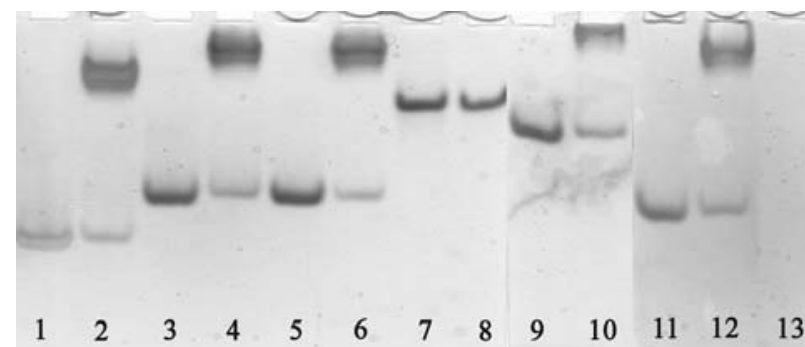

Fig. 4. Analysis of HRN and HRC complexes by $15 \%$ tricine native PAGE. Concentration of individual peptides was 100 $\mu M$. The samples were incubated at room temperature for 20 minutes before being analyzed by native PAGE. The peptide lanes are shown as: 1. HRC1; 2. HRN+HRC1; 3. HRC2; 4. $H R N+H R C 2 ;$ 5. HRC3; 6. HRN+HRC3; 7. HRC4; 8. $H R N+H R C 4 ;$ 9. HRC5; 10. HRN+HRC5; 11. HRC; 12. $H R N+H R C ;$ 13. HRN. 
native PAGE. The results are shown in Figure 4 and Table 1. HRC or HRC analogs alone showed a band in the lower part of the gel. With the exception of HRC4, the mixture of HRC analogs and HRN showed two bands: the lower one had the same position as isolated HRC analog, and the upper band is higher order oligomeric complex formed by HRN and HRC analog. HRN alone showed no band because it carries a net positive charge under the native electrophoresis conditions, and consequently does not enter the gel.

Table 1. Summary of HRC analogs and interaction with HRN

\begin{tabular}{|c|c|c|c|c|c|c|c|c|}
\hline \multirow{2}{*}{$\begin{array}{l}\text { Peptide } \\
\text { Name }\end{array}$} & \multicolumn{2}{|c|}{$[\theta]_{222}{ }^{a}$} & \multicolumn{2}{|c|}{$\% \alpha$ helix $^{b}$} & \multirow{2}{*}{$\begin{array}{l}\mathrm{Tm}^{\mathrm{c}} \\
\left({ }^{\circ} \mathrm{C}\right)\end{array}$} & \multicolumn{2}{|c|}{$\begin{array}{c}\text { Complex with } \\
\text { HRN }\end{array}$} & \multirow{2}{*}{$\begin{array}{c}\text { Complex } \\
\text { formation tested } \\
\text { by Native PAGE }\end{array}$} \\
\hline & Benign & $50 \% \mathrm{TFE}$ & Benign & $50 \% \mathrm{TFE}$ & & $\begin{array}{l}\mathrm{Tm} \\
\left({ }^{\circ} \mathrm{C}\right)\end{array}$ & $\begin{array}{l}\Delta \mathrm{Tm} \\
\left({ }^{\circ} \mathrm{C}\right)\end{array}$ & \\
\hline HRC & -21370 & -29720 & 61 & 85 & 37 & 85 & 0 & + \\
\hline HRC 1 & -32060 & -31510 & 92 & 90 & 57 & 74 & -11 & + \\
\hline HRC 2 & -27060 & -29740 & 77 & 85 & 48 & 86 & +1 & + \\
\hline HRC 3 & -30900 & -31450 & 88 & 90 & 66 & 75 & -10 & + \\
\hline HRC 4 & -28560 & -30990 & 82 & 89 & 74 & 59 & -26 & - \\
\hline HRC 5 & -27770 & -32320 & 80 & 92 & 41 & 88 & +3 & + \\
\hline
\end{tabular}

a. $[\theta]_{222}$ is the mean residue molar ellipticity $\left(\operatorname{deg} \mathrm{cm}^{2}\right.$ dmol $\left.\mathrm{l}^{-1}\right)$ measured at $222 \mathrm{~nm}$ in a 100 $m M$ PBS, $p H 7.0$, in the absence (benign) or presence of $50 \% \operatorname{TFE}(v / v)$. Concentration of peptides was $70 \mu \mathrm{M} . \quad$ b. $\% \alpha$ helix was calculated from $[\theta]_{222}$ based on an ellipticity value for $100 \% \alpha$-helical content derived from the equation, $X H n=X H \infty(1-k / n)$, where $X H \infty$ is $-37,400$, the wavelength dependent constant, $k$, is 2.5 , and $n$ is the number of residues in the helix. c. Tm is the temperature at which there is a $50 \%$ decrease in fraction folded compared to the fully folded coiled-coil as determined by $C D$ at $5{ }^{\circ} \mathrm{C}$.

\section{Conclusions}

1. The substitutions/modifications have increased the HRC $\alpha$-helical structure and stability. As shown in Table 1, the results from CD and native PAGE suggested HRC2 and HRC5 have increased binding affinity with HRN.

2. The two analogs, HRC2 and HRC5, will now be tested as peptide fusion inhibitors in an antiviral activity assay.

\section{Acknowledgments}

This work was supported by NIH grants to R.S.H. (PO1AI059576) and the John Stewart Chair in Peptide Chemistry. We thank Dziuleta Cepeniene for help with peptide synthesis.

\section{References}

1. Tripet B., et al. J. Biol. Chem. 279, 20836-20849 (2004).

2. Xu Y., et al. J. Biol. Chem. 279, 49414-49419 (2004).

3. Bosch, B.J., et al. Proc. Natl. Acad. Sci. USA 101, 8455-8460 (2004).

4. Chan, D.C. and Kim, P.S. Cell 93, 681-684 (1998).

5. Ingallinella, P., et al. Proc. Natl. Acad. Sci. USA 101, 8709-8714 (2004). 